\title{
Features of Childhood Growth, Lifestyle, and Environment Associated with a Cardiometabolic Risk Score in Young Adults
}

\author{
Staffan Mårild ${ }^{a} \quad$ Agneta Sjöberg $^{b} \quad$ Kerstin Albertsson-Wikland ${ }^{c}$ \\ John E. Chaplin ${ }^{a}$ Lauren Lissner ${ }^{d}$ Jovanna Dahlgren ${ }^{\mathrm{a}}$
}

\begin{abstract}
aDepartment of Paediatrics, Institute of Clinical Sciences, The Sahlgrenska Academy, University of Gothenburg, Gothenburg, Sweden; 'bepartment of Food and Nutrition, and Sport Science, University of Gothenburg, Gothenburg, Sweden; 'Institute of Neuroscience and Physiology, Department of Physiology/Endocrinology, The Sahlgrenska Academy, University of Gothenburg, Gothenburg, Sweden; Institute of Medicine, School of Public Health and Community Medicine, The Sahlgrenska Academy, University of Gothenburg, Gothenburg, Sweden
\end{abstract}

\section{Keywords}

Growth patterns · Metabolic syndrome · Adolescents .

Adiposity rebound $\cdot$ Waist circumference $\cdot$ Lifestyle

\begin{abstract}
Introduction: In young adults, metabolic syndrome (MS) is rare. To better assess the risks for future cardiovascular disease (CVD), a cardiometabolic score can be used, ranking the disease risk in each subject. The score is a continuous variable, summarizing the individual $z$-scores for waist circumference, blood pressure, blood levels of glucose, triglycerides, and high-density-lipoprotein cholesterol. Our main aim was to assess the association between early childhood growth and the cardiometabolic score in young adults. Methods: Study participants were recruited among subjects in the longitudinal population-based GrowUp 1990 Gothenburg study. Those with information on weight and length at birth, as well as weight, height, waist circumference, and parental body mass index (BMI) at 10 years of age were invited to participate in a health survey at 18-20 years of age. Five hundred and thirteen young adults (female $51 \%$ ) were included. Multivariable linear stepwise regression analysis was applied. Results: The mean (standard deviation) BMI was
\end{abstract}

karger@karger.com www.karger.com/ofa

Karger"

BOPEN ACCESS
(C) 2021 The Author(s)

Published by S. Karger AG, Basel

This article is licensed under the Creative Commons Attribution 4.0 International License (CC BY) (http://www.karger.com/Services/ OpenAccessLicense). Usage, derivative works and distribution are permitted provided that proper credit is given to the author and the original publisher.
$22.2(3.26)$ in males and $21.3(2.69) \mathrm{kg} / \mathrm{m}^{2}$ in females; the cardiometabolic score was 0.24 (3.12) and -0.22 (3.18), respectively. A statistically significantly higher score $(p<0.001)$ was seen in individuals with MS, as defined by IDF. After controlling for adult lifestyle features, the BMI $z$-score at 10 years of age was a significant risk factor in both sexes for an elevated cardiometabolic score in early adulthood with mean [standard error] beta 0.47 [0.19], $p=0.014$ in males, and 0.82 [017], $p<0.0001$ in females. In males, a high maternal BMI and low age at adiposity rebound and in females, high birth weight were also associated with a statistically significant risk. Additionally, contraceptive use in females was a risk factor for an elevated cardiometabolic score and in males, a high lifestyle-related index score showed a protective association with the cardiometabolic score. Conclusion: A high BMI $z$-score at 10 years of age is a risk factor for the cardiometabolic state in young adults, an outcome pointing to the preventive potential of monitoring BMI in 10-year-old schoolchildren. This finding must however be validated in a new large cohort. Moreover, in young adults in whom MS is rare, the cardiometabolic score seems to be a promising and more powerful tool to detect risks for CVD later in life than using MS categorization.

(c) 2021 The Author(s).

Published by S. Karger AG, Basel
Correspondence to:

Staffan Mårild, staffan.marild@ @ediat.gu.se 


\section{Introduction}

The global prevalence of overweight and obesity among children and adolescents has increased since the latter part of the twentieth century [1]. Childhood overweight and obesity track into adulthood [2] and are risk factors for cardiovascular disease (CVD) through the adult life course [3]. An elevated body mass index (BMI) as early as 9 years of age predicts subclinical arteriosclerosis in adulthood [4]. Genetic traits [5] and environment-related stress are important etiologic factors associated with the development of adiposity and associated metabolic disturbances [6]. The physical and metabolic changes linked to metabolic syndrome (MS) develop gradually from childhood onwards [7]. The prevalence of MS varies by age and sex; it occurs in approximately 2-9\% of school-age children [8], increasing throughout life to about $20 \%$ in men and $40 \%$ in women at 60 years of age [9]. The low prevalence in young people, the age-related increase, and the lack of general agreement on the definition of MS in adolescence [10] have given rise to other tools for early identification of the risk for CVD in adolescents $[11,12]$. These instruments compute a continuous variable that summarizes the relative contribution of the 5 cardiometabolic markers utilized in the traditional MS definitions, i.e., central obesity, high-density-lipoprotein (HDL) cholesterol, triglycerides (TG), blood pressure, and HOMA or blood glucose, in some cases also combined with measures of cardiorespiratory fitness.

The objective of the study was to assess the predictive impact, differentiated by sex, of hereditable traits, parental BMI, and early childhood growth patterns on a cardiometabolic score in a population of young adults and evaluate the relationship of these early influences to selected adult-age lifestyle-related factors. The second aim was to study the relation between the cardiometabolic score and MS by standard definitions in young adults.

\section{Methods}

The GrowUp 1990 Gothenburg Cohort, Enrolment Cohort to the Present Sub-Study

(An outline of the study enrolment is given in a flow chart in online suppl. Fig. 1; for all online suppl. material, see www.karger. com/doi/10.1159/000520661)

The starting point for the GrowUp 1990 Gothenburg study was an epidemiological study in 2000-2001 to assess the prevalence of overweight and obesity in 10-year-old children [13]. In that study, the number of participating children living in the city of Göteborg was 4,731 , corresponding to $84 \%$ of the census-registered population. Weight, height, and waist circumference (WC) at 10 years of age were measured by trained nurses in a health care school; the parental BMI was obtained by a questionnaire. In addition, documented measurements of weight and height from 0 to 10 years of age were retrieved retrospectively for these children from earlier visits at health care centres. A second survey was performed of the children in the cohort when they were 14 years of age, where weight, height, and WC were measured. A third survey occurred when the participants in the cohort were 18-20 years of age, with measurements of height and weight, and completion of a self-report questionnaire on family-related health history. The merged total data set from these different sources constitute the "GrowUp 1990 Gothenburg Study" analytical data set [14].

The GrowUp Metabolic Health Study, i.e., a Sub-Study of the GrowUp 1990 Gothenburg Study

The population in the present study is a subsample of the ongoing GrowUp 1990 Gothenburg cohort study [14]. Eligible subjects in the sub-study were those who had participated in the initial study mentioned above [13], and were residents in the city of Gothenburg at 10 years of age $(n=4,731)$, had complete information on height, weight, WC, parental BMI at 10 years of age, and information on length and weight at birth. A total of 1,685 subjects met these criteria. It was possible to trace 1,083 of them through school records in the city of Gothenburg. These subjects, 18-20 years of age, were invited during 2009-2010 to an additional examination, on top of the one in the GrowUp study mentioned above, with a more detailed medical and laboratory check-up. Informed consent was obtained from 526 of the 1,083 subjects. A special field team for this study visited the schools of these students to repeat measuring height and weight. They also measured WC, blood pressure, arranged laboratory testing using an on-the-spot point-of-care device, and administered questionnaires on family, heredity, medication, and some lifestyle and social-life issues. The final study population with complete data consisted of 513 subjects.

\section{Anthropometric Measurements}

Retrospective data from different health care settings were retrieved from the GrowUp 1990 Gothenburg study [13-15]. Maternity care records provided data on the birth length and weight, as measured by a midwife; paediatric nurses at the child or school health centres recorded the height and weight at visits between birth and 10 years of age, and furthermore, the WC was measured at 10 and 14 years of age. Additional data were available from parental reports of their own age, height, weight, and biological relation to the child collected at the health examinations when the children were 10 and 14 years of age.

In the detailed medical follow-up for the present study, mentioned above, a second examination was done by trained research nurses, at about half a year after the survey in "the GrowUp 1990 Gothenburg study." Body height was measured to the nearest 0.1 $\mathrm{cm}$ using a stadiometer (SECA 225). Body weight in light clothing was measured to the nearest $0.1 \mathrm{~kg}$ using a Tanita scale (Tanita BC 420 SMA, Tanita Europe GmbH, Sindelfingen, Germany). The WC was measured without clothing to the nearest $0.1 \mathrm{~cm}$ using a measurement tape placed at a horizontal line midway between the lowest rib and the iliac crest [16].

\section{Blood Pressure}

Blood pressure was measured by a standardized procedure [17] using an automated oscillometric device (Welch Allyn 4200B-E2, 
Skaneateles Falls, Welch Allyn Inc., NY, USA) [18]. Two records were taken 2 min apart; an extra record was taken in case of a difference of $>5 \%$ in blood pressure between the 2 previous readings. The average of 2 of these measurements was used for statistical analysis. The mean arterial pressure $z$-score was calculated using British reference values [19].

\section{Laboratory Variables by Point-Of-Care Devices}

Blood glucose $(\mathrm{mmol} / \mathrm{L})$, total cholesterol $(\mathrm{mmol} / \mathrm{L}), \mathrm{HDL}$ cholesterol $(\mathrm{mmol} / \mathrm{L})$, and TG $(\mathrm{mmol} / \mathrm{L})$ were assessed on site by point-of-care analysis using the Cholestech LDX analyser (Cholestech, Hayward, CA, USA), either in venous or in capillary blood [20]. $Z$-scores for the crude laboratory values were calculated using published reference values to create $z$-glucose [21], $z$-HDL, and $z$-TG [22].

\section{Definition of Growth-Related Variables}

The formula to calculate BMI is as follows: BMI $\left(\mathrm{kg} / \mathrm{m}^{2}\right)$ : weight $(\mathrm{kg})$ divided by height squared $(\mathrm{m})$. The cut-off for overweight at 10 years of age was BMI $\geq 20 \mathrm{~kg} / \mathrm{m}^{2}$ [23]. Ponderal index $\left(\mathrm{kg} / \mathrm{m}^{3}\right)$ was calculated as weight $(\mathrm{kg})$ divided by length ${ }^{3}$ (metres). The BMI $z$-score (or BMI standard deviation score [BMI SDS]) was calculated as the difference of individual BMI and the sex-age equivalent reference mean divided by the reference SD using Karlberg et al. [24] as the reference. The Natonal Swedish reference for weight and length/height $\mathrm{z}$-scores or SDSs used for ages 0-24 months was [25] and [26] for ages 2-18 years. The waist/height ratio was calculated as waist in centimetres divided by height in centimetres. The waist $z$-score was calculated using Brannsether [27] as the reference. The age and the corresponding BMI $z$-score at the adiposity rebound (AR) were defined as the age where repeated longitudinal BMI measurements changed from a down- to an upward turn, i.e., provided that 2 BMI measures were $\geq 0.5$ BMI units, above the lowest point. If no increase in BMI was observed, no age at AR was possible to define. A computer programme was developed by a data programmer (B.B.) in SAS 9.3. The outcome of the programme was compared repeatedly with visual AR age determinations by the authors J.D. and S.M., followed by adaptation of the programme for a better fit. Finally, the BMI curves of 80 participants were assessed by the final programme and checked visually again. A comparable outcome was seen in 71 subjects. For each child, AR was defined by both age (years) and the BMI $z$-score at the rebound. Growth patterns are presented as the change of the body weight $\mathrm{z}$-scores or SDS between $0-2,0-5,0-10,2-5$, and 5-10 years of age. Measures were selected to be within \pm 0.5 years at 2 and 5 years of age and within \pm 0.99 years at 10 years of age. Catch-up and catch-down growth between 0 and 2 years of age were defined according to Ong [28].

\section{The Cardiometabolic Score}

A continuous cardiometabolic score was created for all study subjects using a modification of an approach published previously [29]. The score is the sum of the individual $z$-scores (or SDS) for adiposity (i.e., waist circumference), blood pressure, glucose, TG, and HDL cholesterol in the blood. External reference values were used to create the different scores, such as waist circumference [27], mean arterial blood pressure [19], HDL cholesterol, TG [22], and glucose [21].

\section{Metabolic Syndrome}

The IDF method was used to define MS [30], modified by insertion of age-relevant reference values [31], i.e., MS is present if at least $3 / 5$ cut-offs are exceeded, e.g., for a 19-year-old male/female with WC $(\mathrm{cm}) \geq 93.8 / 79.8$, TG $\geq 1.68 \mathrm{mmol} / \mathrm{L}$, HDL-C $<1.03 / 1.29 \mathrm{mmol} / \mathrm{L}$, blood pressure $\geq 130$ systolic or 85 diastolic, and fasting glucose $\geq 5.6 \mathrm{mmol} / \mathrm{L}$. The ATP III definition [32] is a generally accepted definition in adults and was used for comparison, i.e., MS if at least 3/5 cut-offs are exceeded, male/female: WC $(\mathrm{cm}) \geq 102 / 88$, TG $\geq 1.7 \mathrm{mmol} / \mathrm{L}$, HDL-C $<1.03 / 1.30 \mathrm{mmol} / \mathrm{L}$, blood pressure $\geq 130$ systolic or $\geq 85$ diastolic, and fasting glucose $\geq 5.6 \mathrm{mmol} / \mathrm{L}$.

\section{Socio-Economic Local Area Index}

At the initial survey, when the children were 10 years old, an area-based socio-economic index was available for all study subjects [13], describing the general socio-economic condition in different subdivisions of the city of Gothenburg. Four such indicators were combined in the index: average income of men 25-49 years old, participation rates in the latest general election, prevalence of single parenthood, and white or blue-collar workers. An in-depth description of the socio-economic index is available [33].

\section{Questionnaires at 18-20 Years of Age}

During the health examination in the metabolic health study, participants responded to a questionnaire on their parent's height and weight as well as parental occurrence of any of the 14 most prevalent diagnoses, including type 2 diabetes, hypertension, and obesity. The participants also responded to open questions regarding their own medical health and pharmacological treatment. The use of contraceptives was specified in females by a yes/no question. The family origin was categorized as Nordic or non-Nordic origin.

A healthy lifestyle-related index was created using the national Swedish food-based dietary guidelines and advice for a healthy lifestyle. Each individual's questionnaire responses to 8 categorical key questions related to diet, physical activity, and sleep were used. Daily intake of sugar-containing soft drinks, including juice or ingestion of fried potatoes $>3$ times a week was given a -1 and water with main meals at least 3 times a day (and no sugar-containing drinks) was given +1 . No breakfast during all 7 days a week was given $\mathrm{a}-1$. $\mathrm{A}+1$ was given for sleep duration of at least 8 hours, TV-time and computer time not more than 1 hour per day, organized training at least 3 times a week, hard physical activity $>10$ min at least 7 times a week, or moderate physical activity $>10$ min at least 7 times a week. The outcome of the 8 questions was added and divided by 8 , i.e., the index ranged from -1 to +1 .

\section{Statistical Methods}

The distribution of continuous variables is presented as mean, SD, quartiles Q1 and Q3, 95\% confidence intervals, and number; for categorical variables, the number and percentages are given. For comparisons between groups, the Mann-Whitney U test was used for continuous variables, Fisher's exact test for dichotomous variables, and the $\chi^{2}$ test for non-ordered categorical variables. The regression analysis was separated by sex, and all significance tests were 2 -sided and conducted at the $5 \%$ significance level.

The primary outcome is the cardiometabolic score. To select independent risk factors for each continuous outcome variable and reduce the number of variables with high collinearity, linear univariable regression analysis was done in a first step on groups 
Table 1. Anthropometric, blood pressure, and laboratory findings at 18-20 years of age

\begin{tabular}{|c|c|c|c|}
\hline Variables & Male $(n=253)$ & Female $(n=260)$ & Difference mean/95\% Cl \\
\hline Age, years & $\begin{array}{l}18.8(0.31) \\
18.6 ; 18.8 n=250^{1}\end{array}$ & $\begin{array}{l}18.8(0.30) \\
18.5 ; 19.0\end{array}$ & $\begin{array}{l}0.021 \\
-0.03 \text { to } 0.07\end{array}$ \\
\hline Weight, kg & $\begin{array}{l}73.8(11.5) \\
66.3 ; 80.2\end{array}$ & $\begin{array}{l}59.7(8.9) \\
54.3 ; 65.0\end{array}$ & $\begin{array}{l}14.08^{* * *} \\
12.30 \text { to } 15.85\end{array}$ \\
\hline Height, $\mathrm{cm}$ & $\begin{array}{l}182.0(6.4) \\
177.9 ; 186.4\end{array}$ & $\begin{array}{l}167.2(6.5) \\
163.0 ; 171.9\end{array}$ & $\begin{array}{l}14.78^{* * *} \\
13.66 \text { to } 15.90\end{array}$ \\
\hline $\mathrm{BMI}, \mathrm{kg} / \mathrm{m}^{2}$ & $\begin{array}{l}22.3(3.3) \\
20.2 ; 23.4\end{array}$ & $\begin{array}{l}21.3(2.7) \\
19.4 ; 22.8\end{array}$ & $\begin{array}{l}0.94^{* * *} \\
0.43 \text { to } 1.46\end{array}$ \\
\hline Waist circumference, $\mathrm{cm}$ & $\begin{array}{l}79.4(8.1) \\
74.0 ; 82.6\end{array}$ & $\begin{array}{l}72.9(7.1) \\
68.5 ; 76.1\end{array}$ & $\begin{array}{l}6.50^{* * *} \\
5.19 \text { to } 7.82\end{array}$ \\
\hline Systolic blood pressure, $\mathrm{mm} \mathrm{Hg}$ & $\begin{array}{l}121.2(9.3) \\
115.0 ; 127.0\end{array}$ & $\begin{array}{l}112.4(7.9) \\
107.0 ; 117.3\end{array}$ & $\begin{array}{l}8.84^{* * *} \\
7.34 \text { to } 10.33\end{array}$ \\
\hline Diastolic blood pressure, $\mathrm{mm} \mathrm{Hg}$ & $\begin{array}{l}71.6(6.5) \\
67.0 ; 75.5\end{array}$ & $\begin{array}{l}70.9(6.1) \\
67.0 ; 75.0\end{array}$ & $\begin{array}{l}0.67 \\
-0.42 \text { to } 1.77\end{array}$ \\
\hline Mean arterial blood pressure, $\mathrm{mm} \mathrm{Hg}$ & $\begin{array}{l}88.1(6.9) \\
83.5 ; 92.3\end{array}$ & $\begin{array}{l}84.7(6.3) \\
80.8 ; 89.0\end{array}$ & $\begin{array}{l}3.39^{* * *} \\
2.25 \text { to } 4.54\end{array}$ \\
\hline HDL cholesterol, $\mathrm{mmol} / \mathrm{L}$ & $\begin{array}{l}1.24(0.32) \\
1.02 ; 1.46 n=251\end{array}$ & $\begin{array}{l}1.52(0.39) \\
1.26 ; 1.77 n=255\end{array}$ & $\begin{array}{l}-0.28^{* * *} \\
-0.34 \text { to }-0.21\end{array}$ \\
\hline $\mathrm{TG}, \mathrm{mmol} / \mathrm{L}$ & $\begin{array}{l}0.94(0.57) \\
0.64 ; 1.16 n=251\end{array}$ & $\begin{array}{l}1.00(0.59) \\
0.64 ; 1.30 n=257\end{array}$ & $\begin{array}{l}-0.06 \\
-0.16 \text { to } 0.04\end{array}$ \\
\hline Glucose, $\mathrm{mmol} / \mathrm{L}$ & $\begin{array}{l}5.46(0.50) \\
5.15 ; 5.81 n=251\end{array}$ & $\begin{array}{l}5.16(0.59) \\
4.80 ; 5.39 n=255\end{array}$ & $\begin{array}{l}0.31^{* * *} \\
0.21 \text { to } 0.42\end{array}$ \\
\hline Cardiometabolic score & $\begin{array}{l}0.24(3.12) \\
-1.80 ; 1.88 n=250\end{array}$ & $\begin{array}{l}-0.22(3.18) \\
-2.18 ; 1.55 n=255\end{array}$ & $\begin{array}{l}0.45 \\
-0.10 \text { to } 1.01\end{array}$ \\
\hline
\end{tabular}

Data for male and female subjects are given as the mean (SD), Q1, Q3, and numbers, when dissimilar from numbers in the heading; the differences between sexes are given as the mean value and the 95 confidence interval. $\mathrm{BMI}$, body mass index; $\mathrm{HDL}$, high-density lipoprotein; TG, triglycerides; SD, standard deviation. Significant differences are indicated by $* * *$, at $p \leq 0.0001 .{ }^{1}$ In 3 male subjects, the date for the survey examination was missing, and no exact age could be calculated

of variables representing different ages or categories (online suppl. Table $1 \mathrm{a}, 1 \mathrm{~b}$ ). Next, the variables with a $p$ value of $<0.01$ or up to the ten most statistically significant variables were included in a stepwise forward multiple linear regression model. The result is presented as a beta coefficient with a standard error for each variable in the model and with $R$-square for the goodness of the model and $p$ values. All statistical analyses were done using version 9.3 of the SAS system for Windows.

\section{Results}

There were 513 study participants who matched the inclusion criteria and formed the "GrowUp metabolic health study" group, a subset of youths from the GrowUp 1990 Go- thenburg study. Data collected at the survey at 10 years of age were used to compare the 513 participants and another 4,214 subjects who had attended the initial survey at 10 years of age, but had not attended the cardiometabolic examination in adulthood (online suppl. Table 2). The metabolic study group had a significantly higher socio-economic position area-level index and a lower mean BMI at 10 years of age, while neither the waist circumference nor distribution by sex differed between the groups. Further descriptive characteristics can be found in online supplementary Tables 3-5.

The mean age of the participants at the health examination was 18.8 years (range 17.8-19.6 years). Sex-related differences were present for anthropometric measures, systolic blood pressure, HDL cholesterol, and blood glu- 
Table 2. Significant $(p<0.01)$ univariate associations between potential risk factors and the cardiometabolic score by gender

\begin{tabular}{|c|c|c|c|c|c|c|}
\hline Potential risk factors & $\beta(S E)$ & R-square & $p$ value & $\beta$ (SE) & R-square & $p$ value \\
\hline AR, age & $-0.47(0.10)$ & 0.08 & $<0.0001$ & $-0.23(0.10)$ & 0.02 & 0.026 \\
\hline AR, BMI SDS & $0.41(0.19)$ & 0.02 & 0.028 & $0.83(0.20)$ & 0.07 & $<0.0001$ \\
\hline Weight SDS at 3 years of age 2 & $0.36(0.20)$ & 0.01 & 0.077 & $0.63(0.23)$ & 0.03 & 0.0058 \\
\hline Weight SDS at 5 years of age ${ }^{2}$ & $0.57(0.19)$ & 0.04 & 0.0028 & $0.79(0.20)$ & 0.06 & $<0.0001$ \\
\hline BMI SDS at 5 years of age $^{3}$ & $0.43(0.19)$ & 0.02 & 0.020 & $0.63(0.19)$ & 0.04 & 0.0009 \\
\hline Change-in-weight SDS between 0 and 10 years of age & $0.46(0.13)$ & 0.05 & 0.0004 & $0.24(0.13)$ & 0.01 & 0.062 \\
\hline Change-in-weight SDS between 5 and 10 years of age & $0.76(0.22)$ & 0.05 & 0.0007 & $0.57(0.20)$ & 0.03 & 0.0054 \\
\hline Weight SDS at 10 years of age ${ }^{2}$ & $0.57(0.13)$ & 0.07 & $<0.0001$ & $0.68(0.14)$ & 0.08 & $<0.0001$ \\
\hline BMI SDS at 10 years of age $^{3}$ & $0.74(0.16)$ & 0.08 & $<0.0001$ & $0.89(0.17)$ & 0.10 & $<0.0001$ \\
\hline Maternal body weight when the child was 10 years old & $0.06(0.02)$ & 0.03 & 0.0040 & $0.06(0.02)$ & 0.03 & 0.0034 \\
\hline Maternal body weight reported at the survey at 18 years of age & $0.21(0.07)$ & 0.03 & 0.0041 & $0.19(0.06)$ & 0.04 & 0.0024 \\
\hline
\end{tabular}

$\beta$, beta value; SE, standard error; R-square, squared regression coefficient; $p, p$ value; SDS, standard deviation score; BMI, body mass index; AR, adiposity rebound. ${ }^{1}$ Reference [25]. ${ }^{2}$ Reference [26]. ${ }^{3}$ Reference [24]. ${ }^{4}$ Reference [22]. ${ }^{5}$ Reference [27].

Table 3. A: Results from multivariable forward stepwise linear regression analyses of risk factors at 10 years of age for the cardiometabolic score (dependent variable) at 18-20 years of age; B: An extended explanatory model in which variables representing the current lifestyle at $18-20$ years of age have been included in model $A$

$\begin{array}{llll}\text { Boys }(n=250) & p \text { Galue } & \frac{\text { Girls }(n=255)}{\beta(S E)}\end{array}$

\begin{tabular}{|c|c|c|c|c|}
\hline BMI $z$-score ${ }^{2}$ at 10 years of age & $0.47(0.19)$ & 0.014 & $0.82(0.17)$ & $<0.0001$ \\
\hline Model A & $n=245, R^{2}=0.12$ & $<0.0001$ & $n=255, R^{2}=0.12$ & $<0.0001$ \\
\hline \multicolumn{5}{|l|}{ B. Variables in explanation model } \\
\hline BMI $z$-score ${ }^{2}$ at 10 years of age & $1.09(0.22)$ & $<0.0001$ & $0.90(0.17)$ & $<0.0001$ \\
\hline Contraceptives at age 18 & & & $0.83(0.38)$ & 0.029 \\
\hline Model B & $n=155, R^{2}=0.15$ & $<0.0001$ & $n=254, R^{2}=0.12$ & $<0.0001$ \\
\hline
\end{tabular}

AR, adiposity rebound; BMI, body mass index; SE, standard error. ${ }^{1}$ Reference [25]. ${ }^{2}$ Reference [24].

cose, while the cardiometabolic score did not differ by sex; its mean (SD) was $0.24(3.12)$ for men and -0.22 (3.18) for women (Table 1).

Fifty-four variables in each sex were tested in a univariate analysis for possible association to the cardiomet- abolic score. Seventeen and 22 variables in male/females had a statistically significant $(p<0.05)$ association with the cardiometabolic score (online suppl. Table 1a, b). Eighteen of these had a $p \leq 0.01$ in either 1 or both sexes (Table 2). In females, the association with smoking and 
Table 4. Mean (SD) of BMI, BMI z-score, and socio-economic area-level index at 10 years of age by sex in overweight or normal-weight subjects and the outcome in these groups at 18-20 years of age of the mean (SD) cardiometabolic score and prevalence of MS

\begin{tabular}{|c|c|c|c|c|c|c|c|}
\hline & \multicolumn{4}{|c|}{ At 10 years of age } & \multicolumn{3}{|c|}{ At $18-20$ years of age } \\
\hline & overweight & BMI & BMI z-score & $\begin{array}{l}\text { socio-economic } \\
\text { index }\end{array}$ & $\begin{array}{l}\text { cardiometabolic } \\
\text { score }\end{array}$ & $\begin{array}{l}\mathrm{MS}^{1} \text { ATP III } \\
n(\%)\end{array}$ & $\begin{array}{l}\text { MS }^{2} \text { IDF } \\
\text { Joliffe } n(\%)\end{array}$ \\
\hline Female & $\begin{array}{l}\text { No, } n=215 \\
\text { Yes, } n=45\end{array}$ & $\begin{array}{l}16.5(1.6) \\
21.9(1.4)\end{array}$ & $\begin{array}{l}-0.29(0.87) \\
1.77(0.35)\end{array}$ & $\begin{array}{l}1.78(3.70) n=202 \\
1.28(3.28) n=42\end{array}$ & $\begin{array}{l}-0.48(3.00)^{\#} \\
1.02(3.71)^{\#}\end{array}$ & $\begin{array}{l}2(1) \\
1(2)\end{array}$ & $\begin{array}{l}6(3) \\
4(9)\end{array}$ \\
\hline Male & $\begin{array}{l}\text { No, } n=211 \\
\text { Yes, } n=42\end{array}$ & $\begin{array}{l}16.9(1.5) \\
22.5(2.2)\end{array}$ & $\begin{array}{l}-0 \text { to } 02(0.92) \\
2.20(0.45)\end{array}$ & $\begin{array}{l}2.37(3.75) n=193 \\
1.05(3.85) n=39\end{array}$ & $\begin{array}{l}-0.09(2.80)^{\&} \\
1.85(4.03)^{\&}\end{array}$ & $\begin{array}{l}2(1) \\
4(10)\end{array}$ & $\begin{array}{l}0 \\
6(14)\end{array}$ \\
\hline MS, totals $(n)$ & - & - & - & - & - & 9 & 16 \\
\hline
\end{tabular}

The cut-off for overweight at 10 years of age was BMI $\geq 20 \mathrm{~kg} / \mathrm{m}^{2}$. BMI, body mass index; SD, standard deviation, $n=$ number, $\%$, per cent; MS, metabolic syndrome. ${ }^{\#}$ Mean difference $(\mathrm{Cl}) 1.22(0.19 ; 2.3) p=0.019 .{ }^{\&}$ Mean difference $(\mathrm{Cl}) 1.68(0.60 ; 2.73) p=0.003 .{ }^{1} \mathrm{MS}$ according to ATP III reference [32]. ${ }^{2}$ MS according to IDF Joliffe reference [31, 30].

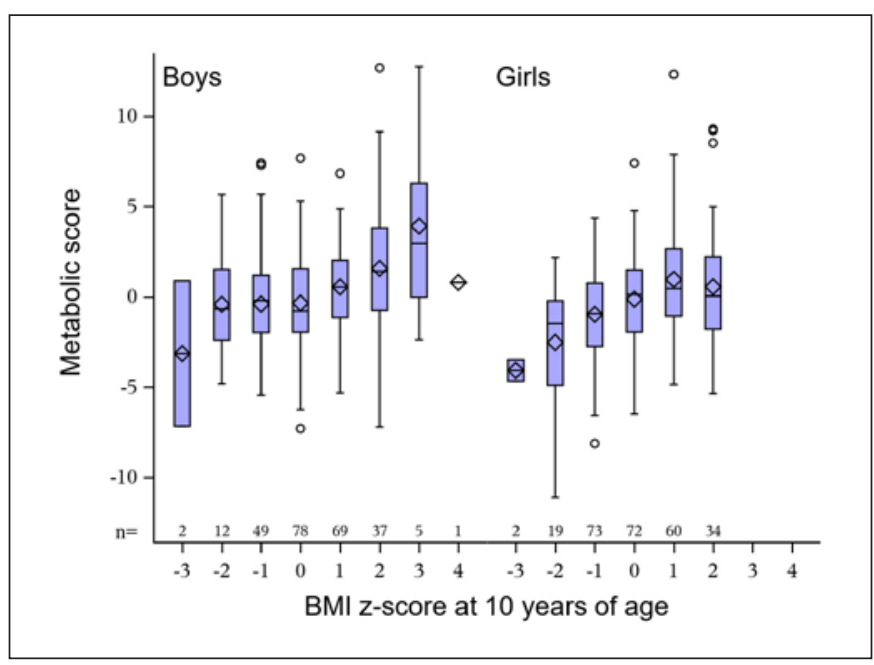

Fig. 1. Relationship between the BMI $z$-score in boys and girls at 10 years of age and the cardiometabolic score at 18-20 years of age. The box plots show the distribution of the score for each unit change in the BMI $z$-score; "diamonds" show the mean, " - " the median, the box top and bottom the 25 th and 75 th percentiles, and the whiskers extend to the minimum and maximum observations within the fence, where the fence is 1.5 IQR below or above Q1 and Q3, respectively; the dots show outliers. The number of observations is shown as $n$. IQR, interquartile range; BMI, body mass index.

contraceptives was weak (not shown, $p=0.049$ and $p=$ 0.044 , respectively).

Variables with statistically significant univariate associations with the score were included in a stepwise forward multiple linear regression model performed separately by sex. In both genders, the BMI $z$-score at 10 years of age emerged as a statistically significant independent risk factor for the cardiometabolic score with a mean [standard error] beta 0.47 [0.19], $p=0.014$ in males and 0.82 [017], $p<0.0001$ in females (Table 3, upper part, A). Birth weight in girls with beta $0.35[0.16], p=0.033$ and, in boys, low age at AR, beta $-0.28[0.12] p=0.019$, and maternal BMI registered at the 10 -year survey, beta 0.14 [0.07] $p=0.036$, were also statistically significant independent risk factors. By forcing lifestyle-related factors, i.e., smoking, use of contraceptives, and the index of diet and physical activity into the initial regression model, an explanatory multivariable regression analysis was achieved ( Table 3, bottom part, B). Here, the BMI $z$-score at 10 years of age in both sexes remained statistically significant, beta 1.09 [0.22] in boys and 0.90 [1.17], $p<$ 0.0001 in girls; the use of contraceptives in females, beta 0.83 [0.38], $p=0.029$, and the diet- and activity-related index in males, beta $-0.51[0.20], p=0.012$, were also statistically significant. Entering BMI at 18-20 years of age into the model wiped out the significances of all other variables, here $R^{2}$ was 0.30 .

The cardiometabolic score was compared by sex in subjects without and with MS according to IDF. In males, the median ( $\min : \max )$ values were $-0.06(-7.3 ; 8.1), n=$ 244 without and $7.72(4.5 ; 12.7), n=6$ with MS, with a mean difference of 8.19 (95\% CI $5.4 ; 11.5)$ and $p<0.0001$. In females, the median ( $\min : \max )$ values were -3.38 $(-11.1 ; 9.2), n=244$ without and $7.07(4.04 ; 12.32), n=$ 10 with MS, with a mean difference of 7.40 (95\% CI 5.6; 9.2) and $p<0.0001$.

The relationship between the BMI $z$-score at 10 years of age in boys and girls and the cardiometabolic score at 
$18-20$ years of age is illustrated in Figure 1 . Subjects categorized as overweight at 10 years of age (BMI $\geq 20 \mathrm{~kg} / \mathrm{m}^{2}$ [23]) had a statistically significant higher cardiometabolic score at 18 years of age (Table 4$)$. In males, the mean (SD) was 1.85 (4.03) and -0.09 (2.8) in those who were above/below this BMI cut-off (the mean difference (CI) $1.68(0.60 ; 2.73) p=0.003$. In females, the mean (SD) was $1.02(3.71)$ and -0.48 (3.0) for those who were non-overweight/overweight at 10 years of age, with a mean difference $(\mathrm{CI})$ of $1.22(0.19 ; 2.3)$ and $p=0.019$.

\section{Discussion}

The major finding in this study is that the BMI $z$-score at 10 years of age was found to be a statistically significant independent risk factor for an elevated cardiometabolic score in very early adulthood in both men and women. Other statistically significant risk factors for an elevated score were high birth weight in females and in males, a low age at AR and elevated maternal BMI. When adding data on lifestyle features in young adulthood into the regression model, the BMI $z$-score at 10 years of age still remained statistically significant in both sexes; in addition, there were other variables significantly associated with an elevated cardiometabolic score: the use of contraceptives in females and in males, low values of the index reflecting features in diet, sleep, and physical activity.

The statistical analysis in the study was stratified by sex. The many sex-related differences in anthropometry in the study population argue for a separate analysis as well as the support presented in previous publications $[21,34]$. Furthermore, at adulthood, there are sex-related differences in the prevalence of MS and in the age spectrum of cardiovascular mortality [35].

The cardiometabolic score in the present study is a modification of a continuous metabolic score described and validated by Eisenmann $[29,36]$. Using this approach, we calculated the cardiometabolic score as the sum of $z$-scores for body components identical to those used to define MS, i.e., adiposity (i.e., waist circumference), blood pressure, glucose, TG, and HDL cholesterol in blood. The different $z$-scores in our study were generated by using externally published Nordic or European age-matched reference values to make the score independent of our specific study population. Interestingly, a large international reference material of common standards for single risk factors for cardiometabolic disease in children has been published recently, which could possibly be used to create a clustered cardiometabolic disease risk score [37]. The cardiometabolic score in our study was statistically significantly higher in subjects with MS than in those without, which points to a possible clinical relevance for the use of the score, but this must be studied further. The cardiometabolic score is possible to use to assign a value to all subjects in a population and thus rank their relative metabolic risk. This is particularly important in young adults, where the levels of MS risk factors are relatively low.

The BMI $z$-score at 10 years of age emerged in multivariable analyses for both sexes as a predictor of the cardiometabolic state in young adults. The importance of tracking of BMI is well documented; we know that children and adolescents with elevated BMI are likely to become adults with overweight or raised BMI [38]. BMI is also a relatively good surrogate marker for adipose tissue [39], which plays a major role in the pathophysiology of MS. In addition, fat mass- and MS-related metabolic markers tend to be parallel in magnitude [40]. Therefore, a direct association between BMI in childhood and later metabolic conditions would be anticipated. In fact, our post hoc study demonstrated that children who were overweight at 10 years of age had a statistically significant higher cardiometabolic score in adulthood, i.e., a direct association between an elevated BMI in childhood to the metabolic state in young adulthood. A recent meta-study also revealed overweight or obesity in childhood to predict the cardiometabolic state or MS in adults [41], and several other studies on the evolution of CVD give support for our findings [34, 42]. The major role of BMI for the metabolic state was moreover demonstrated by entering the actual BMI at 18 years in the regression model, making all other predictors non-significant.

Waist circumference measures were in the normal range in this relatively healthy study population and did not emerge as a risk factor for an elevated cardiometabolic score. A strong overlapping between the 2 adiposity measures, waist circumference, and BMI $z$-score is one likely reason for this. Similar results have been published previously $[21,43]$, where the waist circumference measured at 9-12 years of age was not found to be more strongly associated than BMI with cardiovascular risk factors analysed at 15-16 years of age [21]. This is in line with a previous study where the predictive power for emergence of CVD later in life did not increase by adding the waist circumference to a model using children's BMI [43].

Other independent risk factors associated with a raised cardiometabolic score were high birth weight in girls and elevated maternal BMI in boys. An inverse association also emerged between age at AR and the score in boys. 
These findings are in line with previous studies $[44,45]$. An early BMI change in childhood from a negative to a positive trend, i.e., an $A R$, is a sign of a more intense weight gain and increase in BMI.

The metabolic state in young adulthood is formed throughout life by a great number of genetic and environmental factors [44]. Aspects of the environmental impact were analysed in the multivariable prediction model by inclusion of variables on health behaviour in adulthood. This "explanatory" model indicated that contraceptives in females and an index of lifestyle, i.e., diet, sleep, and physical activity behaviour, in males, were additional independent determinants of the cardiometabolic score. The synthetic sex steroids used in contraceptives have metabolic effects on insulin resistance and lipoproteins, effects most likely avoided in more recent contraceptive products. Still, possible side effects cannot be excluded [46]. It could be that these are safe in normal-weight individuals without any heredity for MS but possibly not in women with an increased metabolic risk, in whom insulin sensitivity may already be disturbed [47]. The role of healthy diet, physical activity, and sleep are already wellknown health promoting factors [48]; however, these factors in the present study displayed only a marginal impact, possibly due to the subjective nature of the data.

The study had limitations as it was designed as a substudy to explore the possible association between growth measures in childhood and the cardiometabolic outcome later in life. The study population was a selection of those attending school in the Gothenburg city and of those with non-missing information on anthropometry at birth and at 10 years of age. This decreased the representativeness. The included subjects had a statistically significantly higher area-level socio-economic index and a lower BMI at 10 years of age than those in the full GrowUp 1990 Gothenburg study cohort, but on the other hand, neither the waist circumference and Ponderal index at birth nor sex distribution differed. This indicates that the present study population is likely to be better off in general health than the original population, potentially underestimating problems related to the cardiometabolic profile and MS. The risk factors and relationships identified in our analyses are therefore likely to have a stronger impact and to be more apparent in a less healthy population.

A strength of this study was the large amount of longitudinal growth data collected in the study population from birth until follow-up at 18-20 years of age, the acquisition of family background data at 10 and 18 years of age, and the detailed health examination at the final follow-up to assess the cardiometabolic score.

Childhood Risk Factors for Adult

Cardiovascular Disease
In conclusion, the present study demonstrates a statistically significant association between the BMI $z$-score at 10 years of age and the cardiometabolic score in young adults. Our findings support the importance of growth and BMI monitoring in schoolchildren as a method for early prevention of elevated BMI later in adolescence as well as evolution of disturbances linked to MS. The results must however be validated in a larger population-based study before being generalized. To use a continuous cardiometabolic score in an essentially healthy population of young adults is a promising approach since all subjects are ranked for the relative risk for CVD rather than detecting the rare occurrence of the overt MS. More research is needed in this area with consensus work and validation studies to find standard methods to compose a cardiometabolic risk score.

\section{Acknowledgments}

We thankfully acknowledge the expert and profound statistical work performed mainly by Bengt Bengtsson; valuable statistical input was also delivered by Nils-Gunnar Pehrson and Valter Sundh. The authors want to thank the field teams led by Marie Lundell (for the metabolic data), Carola Pfeiffer (the GrowUp 1990 Gothenburg study), and Lillemor Ljungberg and Lydia Dahlgren for data support.

\section{Statement of Ethics}

Before any study procedures occurred, written informed consent was obtained from all participants, and if they were under 18 years of age, it was also obtained from their legal guardians. The regional Ethics Committee at the University of Gothenburg granted an ethical approval for the present study as an amendment (Ad 444-08, T062-09) to the ethical approval (Dnr 444-08) of the GrowUp 1990 Gothenburg study.

\section{Conflict of Interest Statement}

The authors have no conflicts of interest to declare.

\section{Funding Sources}

The main study was supported by a generous grant from the Mary von Sydow Research Fund. The GrowUp 1990 Gothenburg study was supported by the following grants: the Foundation Växthuset for Children, the Swedish Research Council (7509, 20067777), the Swedish Council for Working Life and Social Research (2006-1624, 2006-1506), FORMAS, the Governmental grants under the ALF agreement (ALFGBG-812951, ALFGBG-719041, and ALFGBG-427731), and the Region Västra Götaland grants.

Obes Facts 2022;15:170-179 


\section{Author Contributions}

Staffan Mårild has contributed with the overall design and conception of the study; in the acquisition, analysis, and interpretation of data; and in initial drafting, including its intellectual content and subsequent revisions of the paper. Agneta Sjöberg has contributed to the conception of the study, the analysis and interpretation of data, and critical revision of the drafted paper. Kerstin AlbertssonWikland is the PI of the GrowUp study. She has contributed to the design and conception of the present study, acquisition and analysis of data, and critical revision of the drafted paper. John E. Chaplin has contributed to the interpretation of data and critical revision of the drafted paper. Lauren Lissner has contributed to the conception of the study, the analysis and interpretation of data, and critical revision of the drafted paper. Jovanna Dahlgren has contributed to designing the study; its conception; acquisition, analysis, and interpretation of data; drafting; intellectual content of the paper; and subsequent revision of the paper. All the authors have approved submission of the present version of the article and agree to be accountable the accuracy of the work.

\section{Data Availability Statement}

The data analyzed in the study are not publicly available since the participants participated on the understanding that access of the data was restricted to the researchers involved in the study at the Gothenburg University. Any enquiries may be sent to the corresponding author.

\section{References}

1 Wang Y, Lobstein T. Worldwide trends in childhood overweight and obesity. Int J Pediatr Obes. 2006;1(1):11-25.

2 Guo SS, Wu W, Chumlea WC, Roche AF. Predicting overweight and obesity in adulthood from body mass index values in childhood and adolescence. Am J Clin Nutr. 2002;76(3): 653-8.

3 Freedman DS, Katzmarzyk PT, Dietz WH, Srinivasan SR, Berenson GS. Relation of body mass index and skinfold thicknesses to cardiovascular disease risk factors in children: the Bogalusa heart study. Am J Clin Nutr. 2009;90(1):210-6.

4 Juonala M, Magnussen CG, Venn A, Dwyer T, Burns TL, Davis PH, et al. Influence of age on associations between childhood risk factors and carotid intima-media thickness in adulthood: the cardiovascular risk in young finns study, the childhood determinants of adult health study, the bogalusa heart study, and the muscatine study for the international childhood cardiovascular cohort (i3C) consortium. Circulation. 2010;122(24):2514-20.

5 Povel CM, Boer JM, Reiling E, Feskens EJ. Genetic variants and the metabolic syndrome: a systematic review. Obes Rev. 2011;12(11): 952-67.

6 Bjorntorp P, Rosmond R. The metabolic syndrome: a neuroendocrine disorder? Br J Nutr. 2000;83(1):S49-57.

7 Peplies J, Jimenez-Pavon D, Savva SC, Buck C, Gunther K, Fraterman A, et al. Percentiles of fasting serum insulin, glucose, HbAlc and HOMA-IR in pre-pubertal normal weight European children from the IDEFICS cohort. Int J Obes. 2014;38(2):S39-47.

8 Tailor AM, Peeters PH, Norat T, Vineis P, Romaguera D. An update on the prevalence of the metabolic syndrome in children and adolescents. Int J Pediatr Obes. 2010;5(3):202-13.

9 Vishram JK, Borglykke A, Andreasen AH, Jeppesen J, Ibsen $H$, Jørgensen $T$, et al. Impact of age and gender on the prevalence and prognostic importance of the metabolic syndrome and its components in Europeans. The morgam prospective cohort project. PLoS One. 2014;9(9):e107294.

10 Ford ES, Li C. Defining the metabolic syndrome in children and adolescents: will the real definition please stand up? J Pediatr. 2008;152(2):160-4.

11 Andersen LB, Harro M, Sardinha LB, Froberg K, Ekelund U, Brage S, et al. Physical activity and clustered cardiovascular risk in children: a cross-sectional study (the European youth heart study). Lancet. 2006;368(9532):299304.

12 Ahrens W, Moreno LA, Marild S, Molnar D, Siani A, De Henauw S, et al. Metabolic syndrome in young children: definitions and results of the IDEFICS study. Int J Obes. 2014; 38(2):S4-14.

13 Marild S, Bondestam M, Bergstrom R, Ehnberg S, Hollsing A, Albertsson-Wikland K. Prevalence trends of obesity and overweight among 10-year-old children in western Sweden and relationship with parental body mass index. Acta Paediatr. 2004;93(12):1588-95.

14 Sjoberg A, Barrenas ML, Brann E, Chaplin JE, Dahlgren J, Marild S, et al. Body size and lifestyle in an urban population entering adulthood: the 'Grow up Gothenburg' Study. Acta Paediatr. 2012;101(9):964-72.

15 Sjoberg A, Lissner L, Albertsson-Wikland K, Marild S. Recent anthropometric trends among Swedish school children: evidence for decreasing prevalence of overweight in girls. Acta Paediatr. 2008;97(1):118-23.

16 World Health Organisation. Physical status: the use and interpretation of anthropometry. Report of a WHO Expert Committee. World Health Organ Tech Rep Ser. 1995;854:1-452.

17 Barba G, Buck C, Bammann K, Hadjigeorgiou C, Hebestreit A, Marild S, et al. Blood pressure reference values for European non-overweight school children: the IDEFICS study. Int J Obes. 2014;38(2):S48-56.

18 Alpert BS. Validation of the welch allyn spot vital signs blood pressure device according to the ANSI/AAMI SP10: 2002. Accuracy and cost-efficiency successfully combined. Blood Press Monit. 2007;12(5):345-7.

19 Jackson LV, Thalange NK, Cole TJ. Blood pressure centiles for Great Britain. Arch Dis Child. 2007;92(4):298-303.

20 Panz VR, Raal FJ, Paiker J, Immelman R, Miles H. Performance of the CardioChek PA and Cholestech LDX point-of-care analysers compared to clinical diagnostic laboratory methods for the measurement of lipids. Cardiovasc J S Afr. 2005;16(2):112-7.

21 Lawlor DA, Benfield L, Logue J, Tilling K, Howe LD, Fraser A, et al. Association between general and central adiposity in childhood, and change in these, with cardiovascular risk factors in adolescence: prospective cohort study. BMJ. 2010;341:c6224.

22 Cook S, Auinger P, Huang TT. Growth curves for cardio-metabolic risk factors in children and adolescents. J Pediatr. 2009;155(3):S626.

23 Cole TJ, Bellizzi MC, Flegal KM, Dietz WH. Establishing a standard definition for child overweight and obesity worldwide: international survey. BMJ. 2000;320(7244):1240-3.

24 Karlberg J, Luo ZC, Albertsson-Wikland K. Body mass index reference values (mean and SD) for Swedish children. Acta Paediatr. 2001;90(12):1427-34.

25 Niklasson A, Albertsson-Wikland K. Continuous growth reference from 24 th week of gestation to 24 months by gender. BMC Pediatr. 2008;8:8.

26 Wikland KA, Luo ZC, Niklasson A, Karlberg J. Swedish population-based longitudinal reference values from birth to 18 years of age for height, weight and head circumference. Acta Paediatr. 2002;91(7):739-54.

27 Brannsether B, Roelants $M$, Bjerknes $R$, Júlíusson $\mathrm{PB}$. Waist circumference and waist-to-height ratio in Norwegian children 4-18 years of age: reference values and cutoff levels. Acta Paediatr. 2011;100(12): 1576-82. 
28 Ong KK, Ahmed ML, Emmett PM, Preece MA, Dunger DB. Association between postnatal catch-up growth and obesity in childhood: prospective cohort study. BMJ. 2000; 320(7240): $967-71$.

29 Eisenmann JC. On the use of a continuous metabolic syndrome score in pediatric research. Cardiovasc Diabetol. 2008;7:17.

30 Zimmet P, Alberti KG, Kaufman F, Tajima N, Silink M, Arslanian S, et al. The metabolic syndrome in children and adolescents: an IDF consensus report. Pediatr Diabetes. 2007; 8(5):299-306.

31 Jolliffe CJ, Janssen I. Development of age-specific adolescent metabolic syndrome criteria that are linked to the adult treatment panel III and International diabetes federation criteria. J Am Coll Cardiol. 2007;49(8):891-8.

32 Grundy SM, Cleeman JI, Daniels SR, Donato KA, Eckel RH, Franklin BA, et al. Diagnosis and management of the metabolic syndrome: an American heart association/national heart, lung, and blood institute scientific statement. Circulation. 2005;112(17):2735-52.

33 Elmen HHD, Niklasson A, Nilsson W. Birth weight for gestational age and sex as a health indicator at local area: social inequality in a swedish city. Int J Health Sciences. 1995;6(3): $117-26$.

34 Baker JL, Olsen LW, Sørensen TI. Childhood body-mass index and the risk of coronary heart disease in adulthood. N Engl J Med. 2007;357(23):2329-37.

35 Pucci G, Alcidi R, Tap L, Battista F, MattaceRaso F, Schillaci G. Sex- and gender-related prevalence, cardiovascular risk and therapeutic approach in metabolic syndrome: a review of the literature. Pharmacol Res. 2017;120: $34-42$.

36 Eisenmann JC, Laurson KR, DuBose KD, Smith BK, Donnelly JE. Construct validity of a continuous metabolic syndrome score in children. Diabetol Metab Syndr. 2010;2:8.

37 Stavnsbo M, Resaland GK, Anderssen SA, Steene-Johannessen J, Domazet SL, Skrede T, et al. Reference values for cardiometabolic risk scores in children and adolescents: suggesting a common standard. Atherosclerosis. 2018;278:299-306.

38 Simmonds M, Burch J, Llewellyn A, Griffiths C, Yang H, Owen C, et al. The use of measures of obesity in childhood for predicting obesity and the development of obesity-related diseases in adulthood: a systematic review and meta-analysis. Health Technol Assess. 2015; 19(43):1-336

39 Neovius MG, Linné YM, Barkeling BS, Rossner SO. Sensitivity and specificity of classification systems for fatness in adolescents. Am J Clin Nutr. 2004;80(3):597-603.

40 Weiss R, Dziura J, Burgert TS, Tamborlane WV, Taksali SE, Yeckel CW, et al. Obesity and the metabolic syndrome in children and adolescents. N Engl J Med. 2004;350(23):236274.

41 Kim J, Lee I, Lim S. Overweight or obesity in children aged 0 to 6 and the risk of adult metabolic syndrome: a systematic review and meta-analysis. J Clin Nurs. 2017;26(23-24): 3869-80.
42 Twig G, Yaniv G, Levine H, Leiba A, Goldberger N, Derazne E, et al. Body-mass index in 2.3 million adolescents and cardiovascular death in adulthood. N Engl J Med. 2016; 374(25):2430-40.

43 Garnett SP, Baur LA, Srinivasan S, Lee JW, Cowell CT. Body mass index and waist circumference in midchildhood and adverse cardiovascular disease risk clustering in adolescence. Am J Clin Nutr. 2007;86(3):54955 .

44 Han JC, Lawlor DA, Kimm SY. Childhood obesity. Lancet. 2010;375(9727):1737-48.

45 Ong KK, Petry CJ, Emmett PM, Sandhu MS, Kiess W, Hales CN, et al. Insulin sensitivity and secretion in normal children related to size at birth, postnatal growth, and plasma insulin-like growth factor-I levels. Diabetologia. 2004;47(6):1064-70.

46 Sitruk-Ware R, Nath A. Metabolic effects of contraceptive steroids. Rev Endocr Metab Disord. 2011;12(2):63-75.

47 Mosorin ME, Haverinen A, Ollila MM, Nordström T, Jokelainen J, Keinänen-Kiukaanniemi S, et al. Current use of combined hormonal contraception is associated with glucose metabolism disorders in perimenopausal women. Eur J Endocrinol. 2020;183(6):61926.

48 Jalali-Farahani S, Amiri P, Akbar HM, Cheraghi L, Karimi M, Azizi F. Effects of a healthy lifestyle education on the incidence of metabolic syndrome in children during a 13-year follow-up. Int J Behav Med. 2018;25(1):13140 . 